\title{
Policy Description for Information Lifecycle Management Focused on Metadata
}

\author{
Tetsuo Tanaka Member (Hitachi,Ltd., t-tanaka@sdl.hitachi.co.jp) \\ Ryoichi Ueda Non-member (Hitachi, Ltd., ueda@sdl.hitachi.co.jp) \\ Toshiko Aizono Non-member (Hitachi, Ltd., aizono@crl.hitachi.co.jp) \\ Kazutomo Ushijima Non-member (Hitachi, Ltd., ushijima@crl.hitachi.co.jp) \\ Ichiro Naitoh Non-member (Hitachi, Ltd., naito@sdl.hitachi.co.jp) \\ Norihisa Komoda Member (Osaka University, komoda@ist.osaka-u.ac.jp)
}

Keywords : Information Lifecycle Management, Metadata, Policy, Service Level

\section{ILM System}

Data retention, regulatory compliance, and security requirements are increasing by explosive information growth and government regulations. Information Lifecycle Management (ILM) has gotten a lot of attention as a solution for these requirements recently. The goal of ILM is to ensure that information is stored on the most effective and appropriate storage medium depending on the service level required in the phase of the life of information.

To achieve the goal of ILM, managers of information have to perform operations such as moving data between disks, changing access permission, periodical backup of data, and so on. It takes thousands of man-hours. This paper propose ILM system that automates the ILM operations using "policy" indicating manages' intension (Fig.1).

\section{Policy Description for ILM}

\subsection{Definition and Approach} definition of policy in this paper.

- policy $=$ condition + action

- action $=$ information type + status

- status $=$ event + transition condition

- event $=$ creation/reference/update/deletion of information | business event $\mid$ date and time

- transition condition $=$ period before/after the event

- action = migration $\mid$ encryption $\mid$ time-stamp $\mid$ access log $\mid$ backup | restore | access permission | shredding

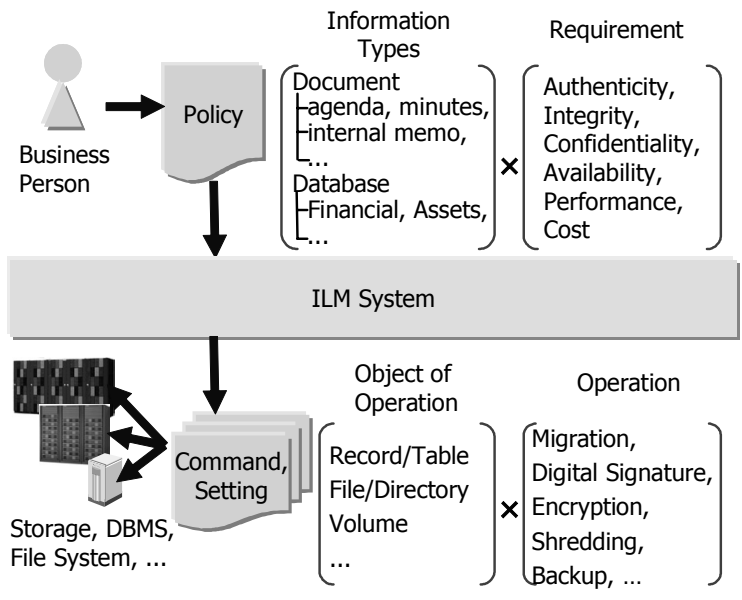

Fig. 1. ILM system
Examples of Policies for office documents and ledgers are shown in Table 1.

Policies are sort of the business-related logic that's the domain of the business person. To describe policies properly, not a system administrator but a manager of information itself i.e. business person should describe them.

Required service level of office documents are closely related with corporate organization and/or business events. In this paper, we focus attention on the close relation. We provide not only metadata of information itself (documents, ledgers and documentation tree) but also metadata of organizations and business events as a vocabulary of policy such as start/end date of projects, organizational hierarchy, role of member, date of business event, and so on.

2.2 Evaluation Man-hours for ILM is shown in Table 2. Using ILM system with business level metadata, all you need to do is one time policy description. You just have to select information type, event, transition condition, and action. It takes just a few minutes. In contrast, using ILM system with system level metadata you should describe a policy for each project or for each ledger. Without ILM system, you should perform operations periodically. It takes several hundred of hours.

Table 1. Examples of policies

\begin{tabular}{|c|l|l|l|l|}
\hline \multirow{2}{*}{$\#$} & \multicolumn{3}{|c|}{ condition } & \multirow{2}{*}{ action } \\
\cline { 2 - 4 } & information & \multicolumn{2}{|c|}{ status } \\
\cline { 3 - 4 } & type & event & transition cond. & \\
\hline 1 & document & last reference & 3 months after & move to low-cost disk \\
\hline 2 & pj. doc & end of pj. & 3 months after & move to low-cost disk \\
\hline 3 & cash book & approval & & $\begin{array}{l}\text { change access permission } \\
\text { "unmodifiable" }\end{array}$ \\
\hline
\end{tabular}

Table 2. Man-hours for ILM

\begin{tabular}{|c|l|c|c|}
\hline$\#$ & $\begin{array}{c}\text { ILM System } \\
\text { (with business level } \\
\text { metadata) }\end{array}$ & $\begin{array}{c}\text { ILM System } \\
\text { (with system level } \\
\text { metadata) }\end{array}$ & manual procedures \\
\hline 1 & $\begin{array}{l}\text { one time description } \\
\text { (a few minutes) }\end{array}$ & $\begin{array}{l}\text { one time description } \\
\text { (a few minutes) }\end{array}$ & $\begin{array}{l}\text { periodical operation } \\
\text { (a few minutes } \times \\
\text { number of times) }\end{array}$ \\
\hline 2 & $\begin{array}{l}\text { one time description } \\
\text { (a few minutes) }\end{array}$ & $\begin{array}{l}\text { one time description } \\
\text { per Pj. } \\
\text { (dozens of minutes } \\
\times \text { num of Pj.s) }\end{array}$ & $\begin{array}{l}\text { periodical operation } \\
\text { per document } \\
\text { dozens of minutes } \\
\times \text { num of times) }\end{array}$ \\
\hline 3 & $\begin{array}{l}\text { one time description } \\
\text { (a few minutes) }\end{array}$ & $\begin{array}{l}\text { one time description } \\
\text { per ledger } \\
\text { (dozens of minutes } \\
\times \text { num of ledgers) }\end{array}$ & $\begin{array}{l}\text { periodical operation } \\
\text { per ledger } \\
\text { (dozens of minutes } \\
\times \text { num of times) }\end{array}$ \\
\hline
\end{tabular}




\section{情報のメタデータに着目した \\ 情報ライフサイクル管理向けポリシー記述方式}

\begin{tabular}{|c|c|c|c|c|c|}
\hline 正 員 & 田中 & 哲雄* & 非会員 & 植田 & 良一* \\
\hline 非会員 & 相薗 & 敏子** & 非会員 & 牛嶋 & 一智** \\
\hline & 藤 & 际 & & & 害久* \\
\hline
\end{tabular}

\section{Policy Description for Information Lifecycle Management Focused on Metadata}

Tetsuo Tanaka*, Member, Ryoichi Ueda*, Non-member, Toshiko Aizono**, Non-member, Kazutomo Ushijima**, Non-member, Ichiro Naitoh*, Non-member, Norihisa Komoda***, Member

Data retention, regulatory compliance, and security requirements are increasing by explosive information growth and government regulations. Information Lifecycle Management (ILM) has gotten a lot of attention as a solution for these requirements recently. The goal of ILM is to ensure that information is stored on the most effective and appropriate storage medium depending on the service level required in the phase of the life of information. And the goal of our research is to automate the ILM process using "policy" indicating managers' intension. This paper proposes the method for description and interpretation of the policy.

キーワード : 情報ライフサイクル管理, メタデータ，ポリシー，サービスレベル，

Keywords : Information Lifecycle Management, Metadata, Policy, Service Level

\section{1. はじめに}

金融業界・医薬業界でのデータ保管に対する法規制の強 化・緩和などにより，情報管理機能の充実が望まれている (1)(2)(3)。例えば，米 SEC ( Securities and Exchange Commission : 証券取引委員会) は規則を改正し, 金融機関 に電子メールなどの電子通信記録の保存を義務付けてい る。また, HIPAA (Health Insurance Portability and Accountability ACT : 電子処理, 医療保険の携行性と責任 に関する法律) では，X線写真などの記録の保管を義務付け ている。国内では, 帳簿類の電子保存を認める $\mathrm{e}$-文書法が 2005 年 4 月に施行された。

また，電子タグやセンシング技術の普及，および企業間

* (株) 日立製作所 システム開発研究所

下 244-0817 神奈川県横浜市戸塚区吉田町 292

Systems Development Laboratory, Hitachi, Ltd.,

292 Yoshida, Totsuka, Yokohama, Kanagawa 244-0817

** (株) 日立製作所 中央研究所

干185-8601 東京都国分寺市東恋ヶ䆶 1-280

Central Research Laboratory, Hitachi, Ltd.,

1-280, Higashi-Koigakubo, Kokubunji, Tokyo 185-8601

*** 大阪大学大学院情報科学研究科

T565-0871 大阪府吹田市山田丘 2-1

Graduate School of Information Science and Technology,

Osaka University,

2-1, Yamada-oka, Suita, Osaka, 565-0871
情報共有の普及により，個品単位でのトレース情報のリア ルタイム, かつ, 広範な収集が可能になりつつあり, 膨大 なトレース情報の迅速な登録・検索，長期間にわたる保管 へのニーズが増大している。

企業のオフィスにおける情報の管理という視点では, 企 業が管理するデータの $80 \%$ 電子メールや文書などの非構 造型データであるとされているが(4)，これらの情報は，個人 の PC で管理されることが多く, データの公開, 引継ぎ, 漏 洩防止, データ保全は個人の裁量に任されている。企業が もつ情報の $60 \%$ が個人の PC に存在するというデータもあ り(5)，それらの系統的な管理が望まれている。

このような背景から，情報の作成から廃棄に至るライフ サイクル全体で，その情報の価值に応じてサービスレベル を設定し活用する， 情報ライフサイクル管理（ILM : Information Lifecycle Management) が注目されている (2)(6)(7)。ILM では，例えば，ミッションクリティカルで，か つ, 頻繁にアクセスするデータは信頼性が高いハイエンド ストレージに保存し, 重要度は高いがそれほどアクセスし ないデータは, アクセス速度が低速でコストパフォーマン スがよいストレージに保存する。重要度が低く, 数力月後 に廃棄するデータは低コストのストレージで保存する。

情報の価值に応じてサービスレベルを設定するには，情 
報の価值が変化する毎に, アクセス権の設定, 暗号化, マ イグレーション (ストレージ間のデータ移動), 圧縮, バッ クアップ, WORM 化 (Write Once Read Many), 完全消去 などの操作（これを情報運用管理と呼ぶ）が必要となる。 これらの操作を膨大な情報に対して, 情報の管理者が人手 で行なうには，膨大な手間がかかる。これに対して，情報 運用管理を自動化する ILM の手法やシステムが提案されて いるが(7), 提案されている方式では, 操作の対象を選択する ための条件の指定方法が, ファイル システムやストレージ システムのメタデータ（ファイルの作成日時, 所有者, 最 終アクセス日時など）に基づくものであり，情報の管理者 であるビジネスパーソンに理解しやすいものとは言えな い。

本研究では，情報運用管理の手間を削減することを目的 とし，情報の管理者が管理の指針（ポリシー）を理解や記 述しや寸い表現で与えると, そのポリシーに沿って上記情 報の操作を自動実行する情報ライフサイクル管理システム

（以下，ILM システム）を提案し，その効果を評価する。

以下, 2.で ILM システムの概要と, その実現に向けての 課題, 本研究のアプローチを述べ, 3.で提案する ILM シス テムにおけるポリシーの記述方式を述べる。4.で提案する方 式の評価を行なう。

\section{2. 情報ライフサイクル管理システム}

〈2·1〉情報ライフサイクル管理＼cjkstart情報は一般に， 「作成」「参照/更新」「公開」「保管」「廃棄」といったライ フサイクルをもつ。このライフサイクルのフェーズと情報 の種類によって, 求められる性能や信頼性, 許容されるコ ストが異なる。また, 求められる機密性, 真正性, 完全性 も異なる。

情報ライフサイクル管理に対するニーズとして, 例えば, 次のようなものがある。

・コスト削減 : 頻繁にアクセスしない保管フェーズにあ る情報は低価格・低速ストレージにおきたい。（コス ト)

・ 利便性向上 : 頻繁にアクセスする参照/更新フェーズま たは公開フェーズにある情報は高速ストレージにおき たい。(性能)

・コンプライアンス対応 : 電子帳簿保存法に基づき, 保 管フェーズにある現金出納帳など経理データの改竄を 防止したい。（完全性）また，データが 5 年ないし 10 年の期間壊れないようにしたい。（信頼性）

- 情報漏洩防止 : 企業秘密や他社の営業秘密は暗号化し て保管し，アクセス履歴を記録したい。廃棄するとき に完全消去したい。（機密性）

- 監查対応 : 文書作成時の作成者や作成日時を記録とし て残したい。（真正性）

これらのニーズを満たすために，ILM では，ストレージ 間のデータの移動や, データの WORM 化, 暗号化などを行 なう。リスト 1 のような研究所のオフィスをモデルとして

\section{リスト 1 研究所オフィスのモデル}

List 1. Model of laboratory office.

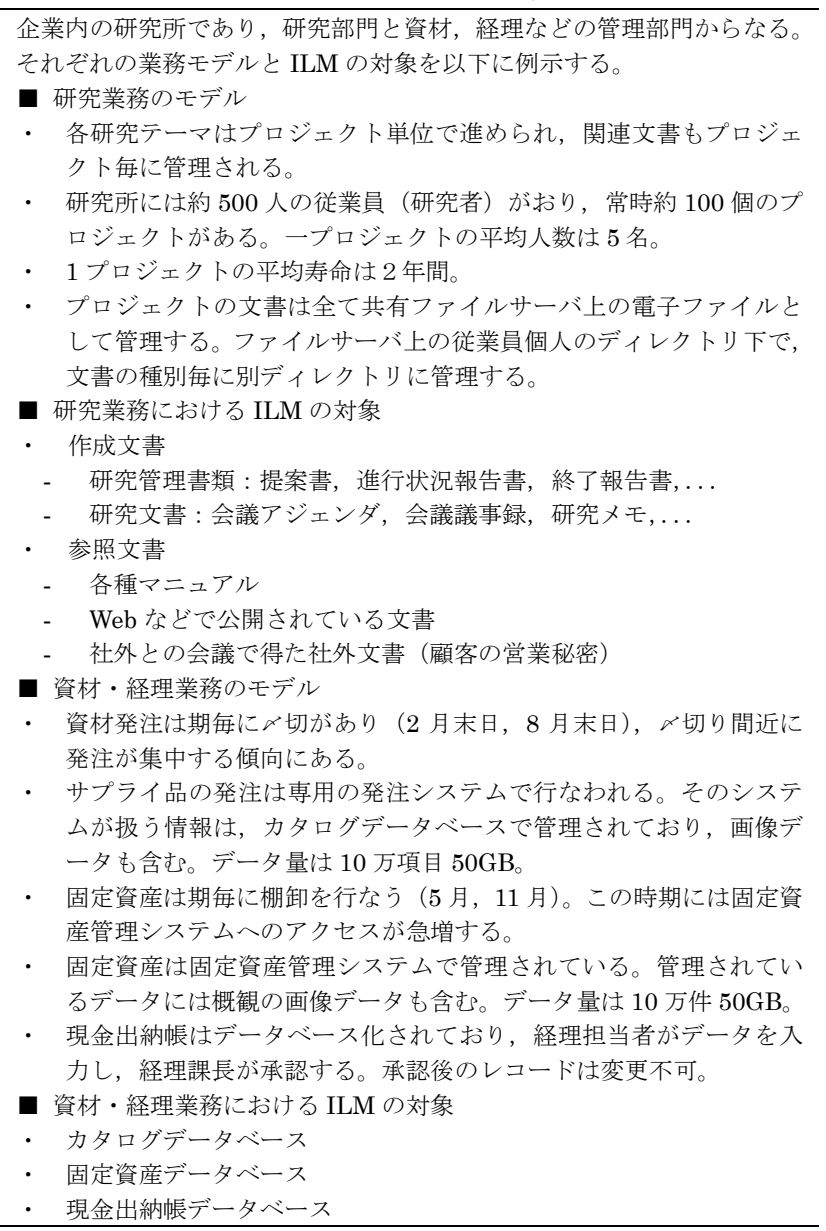

ILM の具体例を示す。図 1 に示すように, 情報の管理には (a)プロジェクトや文書のライフサイクルに依存するもの (下記および図 1 中の(1)-(5)), (b)業務フローに依存するも の (同(6)), 及び, (c)カレンダーに依存するもの（同(7)-(8)) がある。

（1）過去 3 ケ月間アクセスがない文書は低価格・低速スト レージに置く。

3 ケ月間アクセスがない文書を検索して移動するのに 2 分かかるとして, 従業員 500 人全員が毎月（年間 12 回）これを実行すると，200 時間/年を要する。

(2) 終了して 3 ケ月が経過したプロジェクトの文書は低価 格・低速ストレージに置く。

これを行うには, 各プロジェクトが終了して 3 ケ月経 過したか否かを判定し, そのプロジェクトのメンバー をプロジェクト期間中の人事異動も考慮して検索し, そのメンバーが管理するプロジェクト文書をファイル サーバから検索し, ファイルを移動する必要がある。 これに 1 時間を要するとし, 毎年 50 のプロジェクト が終了する（プロジェクトの平均寿命は 2 年間）とす ると, 50 時間/年を要する。

（3）終了して 1 年以上が経過し, 関連文書へのアクセスが 
(a) project-lifecycle-dependent ILM

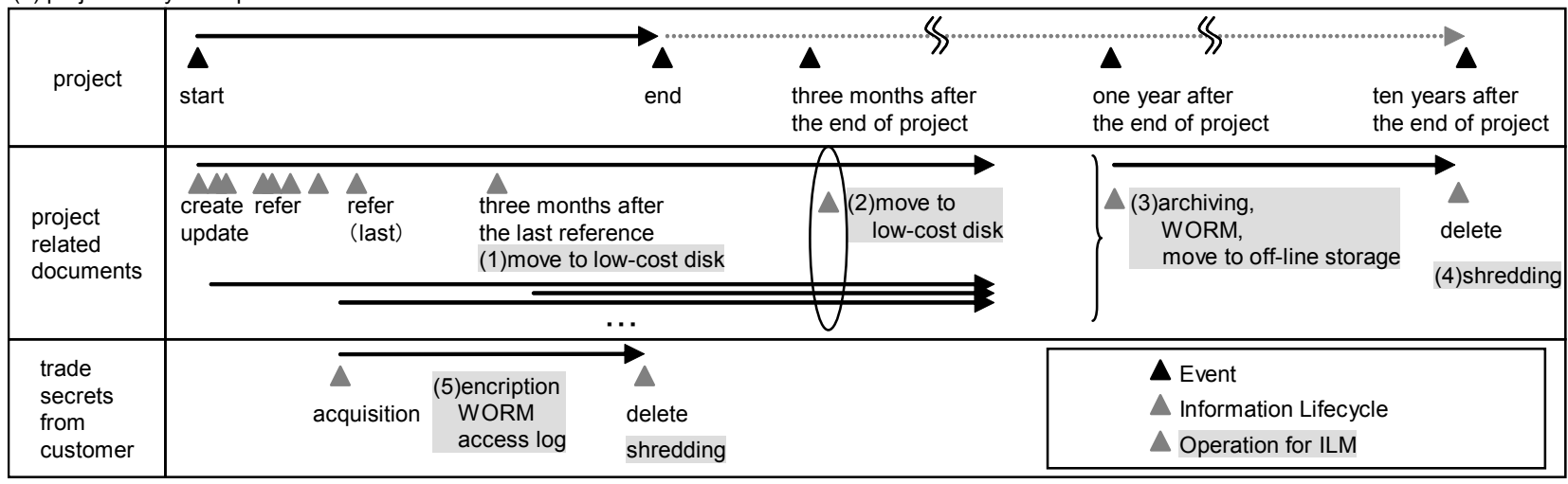

(b) business-process-dependent ILM

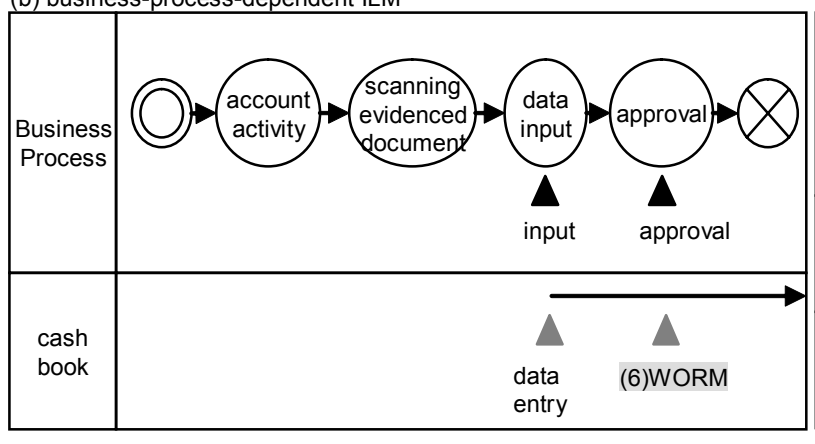

(c) calendar-dependent ILM

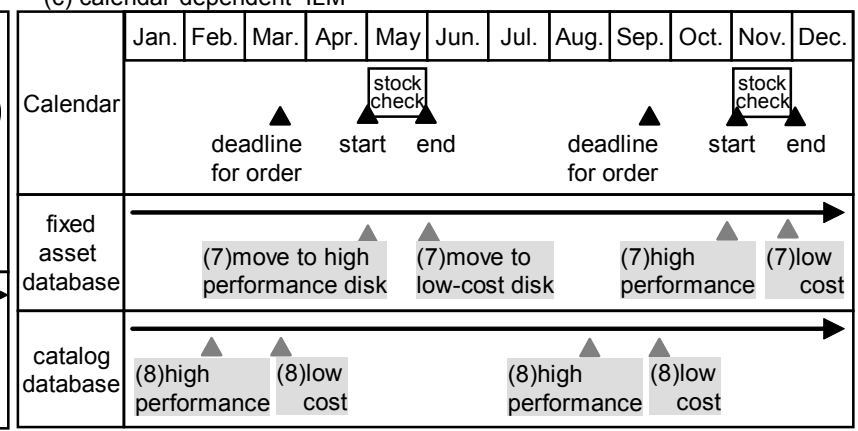

図 1 情報ライフサイクル管理の例

Fig. 1. Examples of information lifecycle management.

ないプロジェクトの文書は，アーカイブし，変更不可 としてオフラインストレージに置く。

その手間は $(2)$ と同様である。

(4) 研究管理書類は, プロジェクト終了から 10 年経過後, 完全消去する。

その手間は(2)と同様である。

（5）顧客空口担当者が入手した顧客資料は，暗号化して保 管する。

これを行うには，顧客資料を入手する毎に暗号化の操 作を行う必要がある。また，担当者が異動などで変更 される場合には，顧客担当者を検索し，その担当者が 顧客資料を管理しているディレクトリを検索し，その ディレクトリを担当者の鍵で複合化してから，それら の文書を新しい担当者に引継ぎ，暗号化しなおす必要 がある。

（6）現金出納帳の経理課長が承認済みの取引記録を変更不 可とする。

このためには, 経理課長が現金出納帳をWORM 化 (一 度書き込んだら，変更できないメディアに書き込むな ど）しなければならない。

（7）固定資産棚卸の時期には，棚卸データを高速ストレー ジに移動する。

期に一度，固定資産管理データベースを移動しなけれ ばならない。

（8）資材発注用カタログ情報は，アクセスが集中する期末 には高速ストレージに移動する。
期に一度, カタログデータベースを移動しなければな らない。

〈2·2〉 ILM システム 本研究で対象とする情報ライ フサイクル管理システム（以下，ILM システム）は $\langle 2 \cdot 1\rangle$ に示したような操作の手間を軽減するために, 情報運用管 理を自動化するものである。

ILM システムは, 図 2 に示すように，情報の管理者が情 報運用管理の指針（ポリシー）を与えると，そのポリシー に沿ってファイルやデータベースを操作する。ポリシーは, 情報の種類とライフサイクル上でのフェーズに応じた要件 である。

ポリシーを適切に設定するためにはストレージやデータ ベースなどのシステムの管理者ではなく，情報そのものの 管理者（ビジネスパーソン）がその要件を判断しなければ ならない。一方, 情報の操作はストレージシステムやファ イルシステム, DBMS などに対するコマンドとして実行さ れる。

したがって，情報の管理者がその意図を反映させること ができる「ポリシー記述方式」と，そのポリシーをシステ ムのコマンドとして実行する「ポリシー解釈実行方式」が 課題となる。

本研究では, ドメインやシステムの知識を提供すること で，ビジネスパーソンの語彙でポリシーを記述可能とする。 ポリシーの解釈実行時には, それらの語彙を上述の知識に より解釈し, ストレージやファイルシステムなどのコマン ドに変換し実行する。 


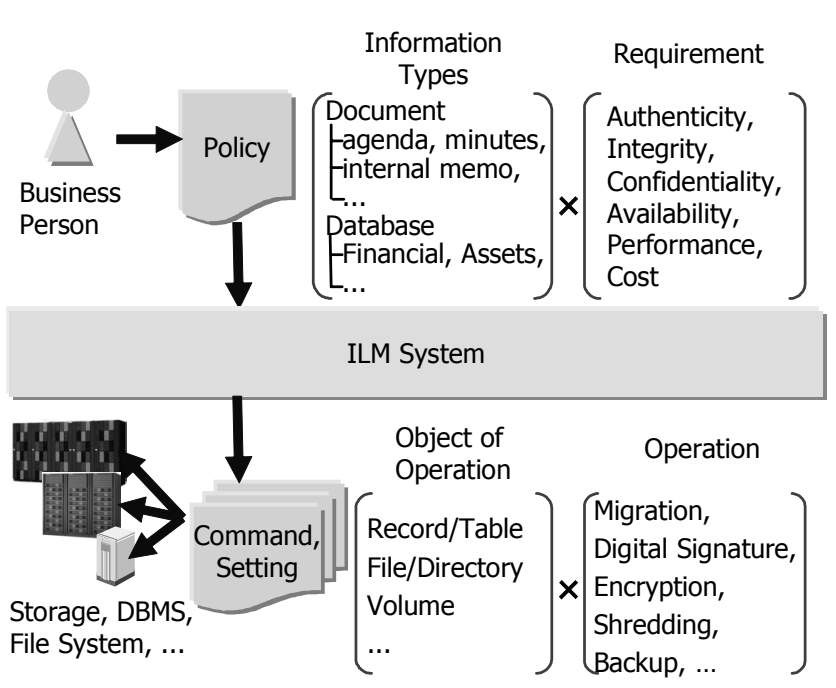

図 2 情報ライフサイクル管理システム

Fig. 2. ILM system.

\section{3. ポリシー記述方式}

〈3・1〉 記述方式 第 2 章ではポリシーを「情報の種 類とそれが満たすべきライフサイクル上での要件」を表す ものとした。しかし，例えば「低いビットコストで管理す る」という要件を満たすには，「低価格ストレージにおく」,

「圧縮する」など複数の操作が考えられる。一般に要件を 満たすための情報の操作は複数あり, 要件を宣言的に述べ たものから, 適切な操作を導出するのは効率が悪い。そこ で，「ある種類の情報がライフサイクル上のあるフェーズ にある場合に，その情報が上記要件を満たすための操作」 を記述したものをポリシーとする。例えば，「3 ケ月間アク セスがない文書の管理コストは低くなければならない」,

「課長承認済みの帳票は書き換えることはできない」など のように宣言的に述べる代わりに，「3 ケ月間アクセスがな い文書は，低価格ストレージに移動する」「課長承認済みの 帳票は WORM メディアに記録する」とする。

定義 1 に示すようにポリシーを条件とアクションの組み とする。ここで, 条件は対象となる情報を絞り込むための 条件であり，アクションは対象となる情報に対する操作で ある。条件は更に情報の種別と状態（情報のライフサイク ル上でのフェーズ）からなるものとする。

情報の種別は, 情報の管理体系におけるその情報の位置 づけを記述する。例えば，オフィス文書においてはオフィ スの文書管理規則などで決められた文書体系における文書 の種別, 業務データでは, 帳簿の体系における帳簿の種別 である。

状態は，状態が推移するきっかけとなるイベントと推移 条件（イベントからの期間，またはイベントまでの期間） として記述する。イベントとしては, (1)情報のメタデータ である作成日時, 更新日時, 参照日時, (2)関連する業務上 のイベントのメタデータである実施日または開始日, 終了 日, (3)特定の日時, の何れかを記述する。業務イベントは,
定義 1 ポリシー

Def. 1. Policy.

\begin{tabular}{ll}
\hline ポリシー $=$ & 条件 + アクション \\
条件 $=$ & 情報の種別 + 状態 \\
状態 $=$ & イベント + 推移条件 \\
イベント = & 情報の作成·参照·更新 | 業務イベント | 時刻 \\
推移条件 $=$ & イベントからの期間 | イベントまでの期間 \\
アクション $=$ & 移動 | 削除 | 属性変更 | バックアップ | \\
& アーカイブ \\
\hline
\end{tabular}

表 1 ポリシー記述用メタデータ

Table 1. Metadata for policy description.

\begin{tabular}{|l|l|}
\hline \multicolumn{1}{|c|}{ Object } & \multicolumn{1}{|c|}{ Metadata } \\
\hline Organization & $\begin{array}{l}\text { Identifier, name, start date, end date, } \\
\text { organizational hierarchy, role, role of a member }\end{array}$ \\
\hline Document & $\begin{array}{l}\text { identifier, name, kind, documentation tree , } \\
\text { degree of secrecy, owner, creation(acquisition) } \\
\text { date and time, last update date and time, last } \\
\text { reference date and time, access permit(AP), } \\
\text { access log }\end{array}$ \\
\hline Ledger & $\begin{array}{l}\text { identifier, name, kind, documentation tree , } \\
\text { degree of secrecy, owner, creation date and time, } \\
\text { last update date and time, last reference date } \\
\text { and time, access permit, access log }\end{array}$ \\
\hline Business Event & name, date (or start date, end date) \\
\hline
\end{tabular}

オフィス文書の例では, プロジェクトの開始や終了, 社内 行事, 各種メ切り, ワークフロー上のアクティビティ（承 認や提出）である。

本研究ではビジネスパーソンの語彙でポリシーを記述で きるようにするために, ドメインの知識を情報そのものや 関連するもののメタデータとして提供する。

例えば, オフィスの活動・業務は組織やビジネスプロセ スと密接に関連し,「オフィス内の情報の種類とそれが満 たすべきライフサイクル上の要件」は, 組織やその組織の メンバーのロール, 文書の種別（文書体系における位置づ け）に依存する。本研究では, このことに着目し, それら の情報を提供することで，ポリシーの記述を容易にする。

すなわち, プロジェクトの開始日時や終了日時などのプ ロジェクトに関するメタデータ, ある従業員がどのプロジ エクトに所属するかなどの従業員とプロジェクトの関係, また, 課長承認済, 部長承認済などビジネスプロセスにお ける状態や, 帳簿の体系における位置づけ（帳簿の種類） に関する情報を提供し，ポリシーの記述を容易にする。

オフィスにおける情報ライフサイクル管理で記述すると 考える様々なポリシーの記述に必要となるメタデータを表 1 に示す。これらの洗い出しにあたっては, リスト 1 のモデ ルを対象として, 文書の運用管理や帳簿の管理で必要とな るメタデータを考察した。

ビジネスパーソンが記述できる語彙を提供するためにオ フィス文書と密接に関連する「組織」「文書」のメタデータ 
を提供する。

前述の ILM のニーズから, アクション部に記述できる操 作を表 2 に示すように決定する。

第 2 章で挙げたポリシーの例を定義 1 に沿って表 1 のメ タデータを利用し記述したものを表 3 に示す。ポリシーの 条件部は, 情報の種別, イベント, 推移条件を選択肢から 選択することにより記述する。その選択肢は定義 1 に示し たものとする。更に情報の種別は情報の体系内の要素, 例 えばオフィス文書の場合, 情報のメタデータである文書体 系の要素 (文書種別), すなわち, 研究管理書類, 議事録, 会議資料などを選択肢とする。また，業務イベントは対象 となる情報に関連するメタデータ，例えばオフィス文書の 場合, 文書の最終アクセス日付, プロジェクトの終了日な どを選択肢とする。

例えば，「(2)終了して 3 ケ月が経過したプロジェクトの 文書は低価格・低速ストレージに置く。」は, 情報の種類が プロジェクト文書, イベントがプロジェクト終了, 推移条 件が 3 ケ月経過, アクションが低価格・低速ストレージへ の移動という形式で記述できる。

〈3·2〉 ポリシーの内部表現とその解釈実行 ILM シ ステムの内部での表現としては，ポリシーは policy という エレメントをもつ XML 形式で記述する。 policy エレメント は name, condition, action のサブエレメントからなる。 各サブエレメントの記述内容は次の通りである。

・ name : ポリシー名

表 2 目的とその実現に要求される操作

Table 2. Objectives and operations.

\begin{tabular}{|l|l|}
\hline Objectives & Operations \\
\hline cost saving & migration to low-cost disk \\
\hline usability & migration to high performance disk \\
\hline compliance & encryption, time-stamp, \\
audit & access log \\
& backup/restore \\
\hline preventing & access permission, \\
information leaks & shredding, encryption \\
\hline
\end{tabular}

ポリシーの名前を文字列で記述

- condition : 条件部

ファイルを選択する条件を記述

・ action : アクション部

ファイルに対するアクションを記述

条件部は RDQL ${ }^{(8)}$ (RDF Data Query Language) を拡張 した記法で記述する。 RDQL は $\mathrm{RDF}^{(9)}$ (Resource Description Framework) のトリプルの集合に対してクエ リを行なうための SQL に似たクエリ言語であり, 次の節を 持つ。

- SELECT 節 : アプリケーションへ返される変数

・WHERE 節 : RDF のトリプルのパターンを指定

・ AND 節 : ブール值をとる式

・ USING 節：長いURI を短縮するための別名を定義

RDQL では，選択したファイルをグループ化し，各グル 一プの要約情報（合計, 平均など）を得るなどの記述がで きないため, 次の節を追加する。

・ GROUP BY 節 : 選択されたトリプルをリソースの值に基 づいてグループ化

・ HAVING 節 : GROUP BY 句でできるグループから, 特定 のグループを選択するための条件を指定

・ ORDER BY 節 : トリプルを指定したリソースの值でソー 卜

アクション部には，条件部で抽出された情報群に対する 操作を次の形式で記述する。

\section{コマンドスクリプト 引数リスト}

コマンドスクリプトとして, 表 2 に示した操作, ファイ ル移動, アクセス許可の変更, ファイル属性変更, ファイ ル削除, ファイル完全消去, 署名付与, タイムスタンプ付 与, アクセス履歴記録開始, 暗号化, バックアップ, リス トアに対応する各コマンドを提供する。

例えば，「終了して 3 ヶ月が経過したプロジェクトのファ イルは低速ディスクに置く」というポリシーはリスト 2 の ような記述となる。

表 3 Policy 記述

Table 3. Policy description.

\begin{tabular}{|c|c|c|c|c|}
\hline \multirow[t]{3}{*}{$\#$} & \multicolumn{3}{|l|}{ Condition } & \multirow[t]{3}{*}{ Action } \\
\hline & \multirow[t]{2}{*}{ Information Type } & \multicolumn{2}{|l|}{ Status } & \\
\hline & & Event & $\begin{array}{l}\text { Transition } \\
\text { Condition }\end{array}$ & \\
\hline (1) & document & last reference & 3 months after & move to low-cost disk \\
\hline (2) & project related document & end of project & 3 months after & move to low-cost disk \\
\hline \multirow[t]{2}{*}{ (3) } & \multirow[t]{2}{*}{ project related document } & end of project & 1 year after & \multirow{2}{*}{$\begin{array}{l}\text { archive, change access } \\
\text { "unmodifiable", } \\
\text { move to off-line storage }\end{array}$} \\
\hline & & last reference of all documents & 1 year after & \\
\hline (4) & research management document & end of project & 10 years after & shred \\
\hline$(5)$ & Trade secret from customer & acquisition & & encrypt \\
\hline (6) & cash book & approval from a supervisor & & change AP "unmodifiable" \\
\hline \multirow[t]{2}{*}{ (7) } & \multirow[t]{2}{*}{ Stock check data } & start of stock check & & move to high performance disk \\
\hline & & end of stock check & & move to low-cost disk \\
\hline \multirow[t]{2}{*}{ (8) } & \multirow[t]{2}{*}{ catalog for purchase order } & deadline for order & 1 month before & move to high performance disk \\
\hline & & deadline for order & & move to low-cost disk \\
\hline
\end{tabular}


リスト 2 ポリシー記述例

List 2. An example of policy.

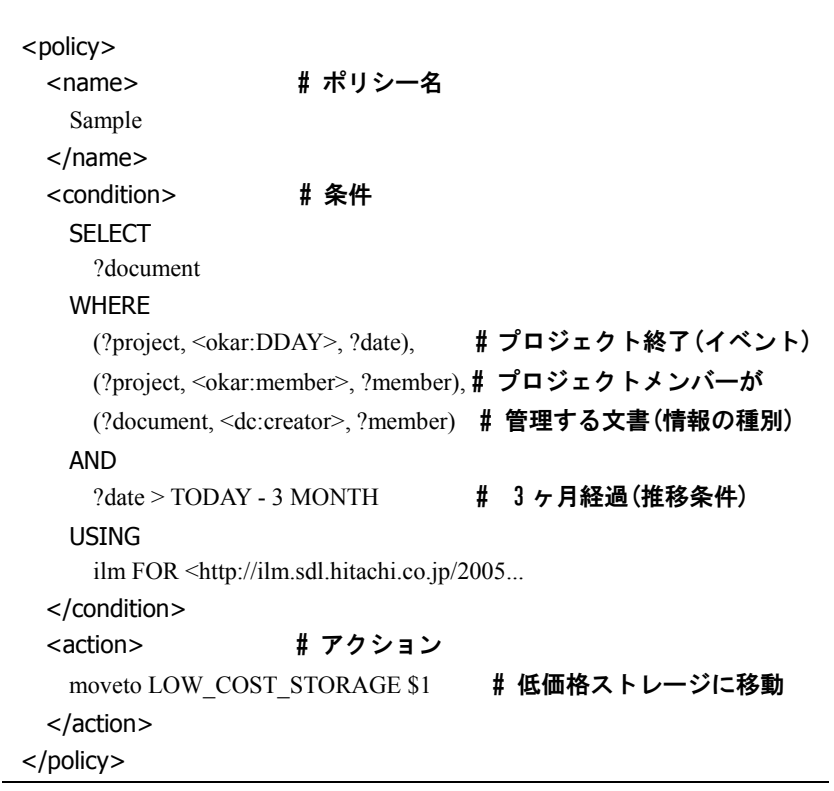

組織や文書, 従業員を記述する際, OKAR(Ontology for Knowledge Activity Resources)(10), Dublin Core ${ }^{(11)}$,

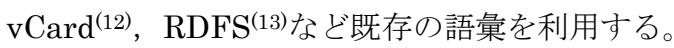

ポリシーの記述は組織や文書のメタデータを利用して記 述するが，実際に操作されるのはストレージ上のファイル である。その操作はファイルやストレージのメタデータに 応じて実行される。したがって, 表 4 に示すようにファイ ル, ストレージ, 従業員のメタデータおよび, メタデータ 間の関係を提供し，ポリシーの解棌実行に利用寸る。メタ データ間の関係には，例えば次のようなものがある。

・「組織」と「組織が管理する文書の文書体系」の対応 関係

・「ディレクトリとファイルの親子関係」と「文書体系」 の対応関係，文書とファイルの対応関係

・ストレージとディレクトリの対応関係（どのディレク トリがどのストレージ (ドライブ) にマウントされて いるかの情報）

・組織における「メンバーのロール」と従業員の対応関 係

ポリシーは次の手順で解釈実行する。

\section{（1）条件部の解䣋}

条件部は「組織」「文書」のメタデータ上の語彙からなる クエリである。メタデータ間の関連を利用し，そのクエリ を「ファイル」のメタデータ上のクエリに変換する。

（2）クエリ（条件部の解釈結果）の実行

(1)で得たクエリを実行し, 操作の対象となるファイル （クエリに合致するメタデータをもつ情報）のリストを得 る。

（3）アクション部の解釈

ストレージなどのコマンドを呼び出すスクリプトを予め
表 4 解釈実行用メタデータ

Table 4. Metadata for interpretation.

\begin{tabular}{|l|l|}
\hline object & metadata \\
\hline employee & identifier, name, user-ID for file server \\
\hline $\begin{array}{l}\text { file } \\
\text { directory }\end{array}$ & $\begin{array}{l}\text { logical-identifier, physical- identifier, } \\
\text { kind (file/directory), path name, } \\
\text { access log (date, time, operation, subject), } \\
\text { size, owner, created date and time, } \\
\text { last update date and time, access permit, } \\
\text { access log }\end{array}$ \\
\hline storage & $\begin{array}{l}\text { Performance, bit cost, modifiability, } \\
\text { ability to shred }\end{array}$ \\
\hline
\end{tabular}

用意する。アクション部はシステムに関する知識（ストレ ージやファイルのメタデータ）上の語彙と上記スクリプト を指寸語彙からなる。それを，それを提供されるメタデー タ間の関連を用いてスクリプトを指す語彙に変換する。

（4）スクリプト(アクション部解釈結果)の実行

スクリプトを実行する（情報に対する操作を実行する）。

\section{4. 評 価}

提案するポリシー記述方式の記述工数，および，ILM シ ステムによって削減される情報運用管理の工数を $\langle 2 \cdot 1\rangle$ に 示した情報運用管理の例(1)〜 (8)で評価する。表 5 に手作業 で行なう場合と ILM システムで実行する場合のそれぞれの 管理の工数を䋔める。表 5 では, ILM システムで行なう場 合をさらに 2 つに分けて記述している。一方は提案する方 式であり, 組織, 文書, 帳簿, 業務イベントなどのメタデ 一タを整備し，ポリシーの記述者に提供する方式である。 これを業務レベルのポリシー記述と呼ぶ。もう一方は，フ アイル名, 管理者, 参照日時などファイルシステムなどが 提供するメタデータのみを利用する方式である。これをシ ステムレベルのポリシー記述と呼ぶ。

〈4・1〉 ポリシー記述工数本稿で提案する業務レベ ルのポリシー記述方式では, ポリシー記述者は, 情報の種 別, イベント, 推移条件, アクションをメタデータから選 択するのみでポリシーを記述できる。例えば, ポリシー例(2) では，表 3 の(2)にあるように，情報の種別としてプロジェ クトの文書体系から「プロジェクト文書」を選択し，イ心゙ ントとして業務イベントから「プロジェクト終了」を選択 し, 推移条件として「3 ケ月経過」を選択肢, アクションと して「低価格・低速ストレージへ異動」を選択するの夕で あり, 数分の作業となる。

これに対し，システムレベルのポリシー記述方式では, 例えばポリシー例(2)では次のことを行なうスクリプトを記 述することとなり, 数十分〜数時間の作業となる。

・ 各プロジェクトの終了年月日を調查 (プロジェクト管理 データベースの検索, プロジェクト管理書類の参照, な

ぞ）し, 該当するプロジェクト（終了して 3 ケ月が経過 したプロジェクト）か否かを判断

・プロジェクトの関連ファイルを特定

>プロジェクトメンバーだったことがある従業員の検 


\section{表 5 ILM の工数}

Table 5. Man-hours for ILM.

\begin{tabular}{|c|l|l|l|}
\hline$\#$ & $\begin{array}{l}\text { ILM System } \\
\text { (business level } \\
\text { policy description) }\end{array}$ & $\begin{array}{l}\text { ILM System } \\
\text { (system level } \\
\text { policy description) }\end{array}$ & manual procedures \\
\hline$(1)$ & $\begin{array}{l}\text { one time } \\
\text { description } \\
\text { (a few minutes) }\end{array}$ & $\begin{array}{l}\text { one time } \\
\text { description } \\
\text { (a few minutes) }\end{array}$ & $\begin{array}{l}\text { periodical operation } \\
\text { (a few minutes } \times \\
\text { number of times) }\end{array}$ \\
\hline$(2)$ & $\begin{array}{l}\text { one time } \\
\text { description } \\
(5)\end{array}$ & $\begin{array}{l}\text { one time } \\
\text { description per Pj. } \\
(\text { dozens of minutes } \\
\times \text { num of Pj.s) }\end{array}$ & $\begin{array}{l}\text { periodical operation } \\
\text { per document. } \\
(\text { dozens of minutes } \\
\times \text { num of times) }\end{array}$ \\
\hline$(6)$ & $\begin{array}{l}\text { one time } \\
\text { description } \\
(8)\end{array}$ & $\begin{array}{l}\text { one time } \\
\text { description } \\
\text { per ledger } \\
(\text { dozinutes })\end{array}$ & $\begin{array}{l}\text { periodical operation } \\
\text { per ledger } \\
(\text { dozens of minutes } \\
\times \text { num of times })\end{array}$ \\
& & $\times$ num of ledgers $)$ & \\
\hline
\end{tabular}

索

> その従業員のファイルサーバにおけるユーザ ID の 検索

> そのユーザID のホームディレクトリ下の, プロジェ クト名と同じ名前を持つディレクトリ以下のファイ ルの検索

また，文書のサーバ内での管理方法やプロジェクトの期 間やメンバーなどの情報の管理方法がプロジェクト毎に異 なる場合, このスクリプトはプロジェクト毎に記述する必 要がある。プロジェクトが 100 個あれば，数千分から数百 時間を要する。

ポリシー例(3)〜(5)はプロジェクトの文書管理に関するも のであり，(2)と同様の議論となる。すなわち，業務レベル のポリシー記述では数分で済むところ, システムレベルの ポリシー記述では, 数十分×プロジェクト数の工数が必要 となる。

ポリシー例(6)〜(8)は業務データベースに関するものであ る。システムレベルのポリシー記述方式では, 総勘定元帳, 現金出納帳, 預金出納帳などの個々の帳簿（データベース） ごとに，ポリシーを記述する必要があるが，業務レベルの ポリシー記述方式では，これらを纏めて経理帳簿という情 報の種別単位でのポリシー記述が可能となる。また，ポリ シーの記述者は現金出納帳, 固定資産などのデータベース が, どの DBMS のどのテーブルとして管理されているかや, 承認済みのレコードはどのカラムがどの值になっているな どのシステム実装の詳細を知る必要がなく, 情報の管理者 自身が理解できる語彙でポリシーを記述できる。

ポリシー例(1)は，条件が最終アクセス日時に関する画一 的なものであり, 業務色が薄いため, 業務レベルのポリシ 一記述とシステムレベルのポリシー記述で, 工数の差は少 ない。

〈4·2〉 ILM システムによって削減される情報運用管理 の工数 ILM を人手で行なう場合の工数と本稿で提案す るシステムを用いる場合で, ILM のための工数を比較する。 ILM を人手で行なう場合の工数は, 〈2・1〉に示したとお
り, 一つのポリシーに関して年間数十時間から数百時間で ある。一方, 本稿で提案するシステムを用いる場合は, ポ リシーを記述すれば，その解釈実行は自動的に行われるた め, ポリシーの記述工数のみである。ポリシーの記述工数 は〈4・1〉に示したとおり，1 ポリシーあたり，数分ですむ。 ポリシーは一度記述すれば，管理の指針が変更されるまで 記述する必要がないので，たとえば 5 年間変更がないとす ると， 1 個のポリシーに基づく管理のためには， 1 年あたり 数分のさらに $1 / 5$ を要するのみである。

また, 人手で行なう場合は, 操作対象の選択や操作その ものを誤ることがあるが, 自動化により, その誤りを防止 することができる。

〈4・3〉適用範囲提案する記述方式では, ポリシー をビジネスパーソンの語彙で記述できるように，ドメイン の知識を管理対象の情報に関連するもののメタデータとし て提供する。表 3 で示したポリシーは, 組織, 文書, 帳票, 業務イベントのメタデータを用いて記述しているため, こ れらのメタデータの項目が同じであるような他の研究所や 組織にも適用可能である。また， $\langle 4 \cdot 1\rangle$ と $\langle 4 \cdot 2\rangle$ では, 500 名の研究者（100 個のプロジェクト）を擁する研究所のオフ イスを例に評価したが，表 5 に示すように，ポリシーはプ ロジェクトの数に依存しない工数で記述でき, したがって, 研究所の規模に関わらず適用可能である。

更に, “ポリシー＝条件（情報の種別+イベント十推移条 件）十アクション”という記述方式は, 研究所のプロジェク 卜文書や業務データベース以外の様々な情報にも適用可能 である。ただし, 情報の種別とイベントは管理対象によっ て異なるため, それらを識別するための情報の体系や業務 モデル（リスト 1 や図 1 に相当）を明確にし，メタデータ （表 1 相当）を整備する必要がある。例えば, 映像ライブ ラリの管理ポリシーを記述するには, 映像の種別を識別す るための管理体系, 及び, 映像の収録・視聴・放送などの 業務イベントを識別するための業務モデルを明確にし, 関 連するメタデータを整備する必要がある。更に, そのポリ シーを解釈実行するには, そのためのメタデータ（表 4 相 当）も整備する必要がある。

情報の体系と業務モデルは, 明文化された組織の規則や 暗黙のうちに実施されている管理規則を分析し策定する。 また，メタデータは，各種業務システムやデータベース， ワークフローシステムなどからシステム連携により収集す る。これら分析の工数やシステム連携のための開発工数は ILM システム構築時に一度発生するのみであり本評価の結 果を大きく変えるものではないと考える。

\section{5. おわりに}

管理のポリシーを与えると, そのポリシーに沿って情報 の操作が可能となるポリシー記述方式を提案した。提案方 式を研究所のオフィスにおける文書管理, 業務データベー スの管理に適用して，その有効性を確認した。

提案する記述方式は, 情報の種別ごとにアクションを記 
述するため, 一つの情報が複数のポリシーの対象となる場 合がある。したがって, それらのポリシーが同時には実行 できないアクション（削除と移動, 高速ストレージへの移 動と低速ストレージへの移動, 永年保管と最終アクセス後 3 年での削除，など）を持つといった矛盾が生じる可能性が ある。これらの矛盾の検出や，ポリシーに矛盾がないこと の検証は今後の課題である。

(平成 17 年 8 月 5 日受付, 平成 17 年 11 月 8 日再受付)

$$
\text { 文献 }
$$

(1) AMR : "AMR Research Predicts Compliance Is an $\$ 80 \mathrm{~B}$ Issue", http://www.amrresearch.com/Content/View.asp?pmillid=18086\&d ocid $=12380,2005 /$

（2）鈴木孝知：「デー夕量の急増で注目集まる $\mathrm{ILM}\rfloor$, 日経コンピュー 夕, 2004.08.23 号, pp.110-113 (2004)

（3）スティーブン・マリーン：「法規制でIT 投資が増加」，日経コンピ ユータ, 2003.12.29 号, pp.17-18 (2003)

(4) Christine Taylor Chudnow : "File systems and storage", Computer Technology Review, Vol.22, No.7, p.30 (2003)

(5) Cynthia Doyle and David Tapper : "Meeting the Enterprise Data Protection Challenge", An IDC White Paper (2002)

(6) Todd Rief : "Information Lifecycle Management", Computer Technology Review, Vol.23, No.8, pp.38-39 (2003)

(7) Mike Palermo : "Policy-based data management in ILM", Computer Technology Review, Vol.24, No.8, pp.20-21 (2004)

(8) W3C : "RDQL - A Query Language for RDF", http://www.w3.org/ Submission/RDQL/

(9) W3C : "RDF Primer W3C Recommendation", http://www.w3.org/ TR/rdf-primer/ (2004)

（10） OKAR ワーキンググループ：「Ontology for Knowledge Activity Resources (OKAR) ガイド ドラフト」, http://www.labs.fujitsu. com/jp/techinfo/okar/guide_draft_20050204jp.pdf (2005)

(11) DCMI : "Dublin Core Metadata Element Set, Version 1.1 : Reference Description", http://dublincore.org/documents/dces/ (2004)

(12) Internet Mail Consortium : "vCard - The Electronic Business Card Version 2.1", http://www.imc.com/pdi/vcard-21.txt (1996)

(13) W3C : "RDF Vocabulary Description Language 1.0 : RDF Schema W3C Recommendation", http://www.w3.org/TR/rdf-schema/ (2004)

田 中 哲 雄 (正員) 1961 年生。1985 年 3 月大阪大学基

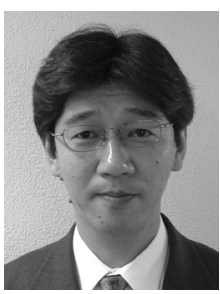
礎工学部情報工学科卒業。1987 年同大学大学 院博士前期課程修了。同年（株）日立製作所入 社。現在, 同社システム開発研究所勤務。情報 ライフサイクル管理, RFID 応用ソリューショ ン等の研究開発に従事。情報処理学会, 電子情 報通信学会各会員。

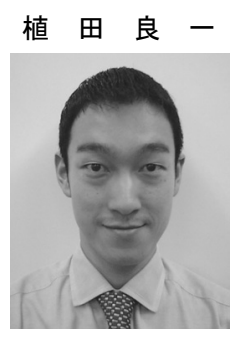

（非会員） 1970 年生。1994 年大阪大学大学院 基礎工学研究科情報工学専攻博士前期課程修 了。同年 (株) 日立製作所に入社。現在, 同社 システム開発研究所勤務。情報ライフサイクル 管理，ストレージ管理技術の研究開発に従事。

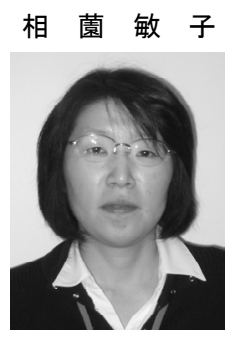

(非会員) 1966 年生。1989 年聖心女子大学文 学部教育学科心理学専攻卒業。1992 年東京工 業大学大学院総合理工学研究科システム科学 専攻修士課程修了。同年(株)日立製作所入社。 システム開発研究所を経て, 現在, 同社中央研 究所勤務。情報ライフサイクル管理, 知識処理, 自然言語処理の研究開発に従事。情報処理学 会, 人工知能学会, 言語処理学会各会員。

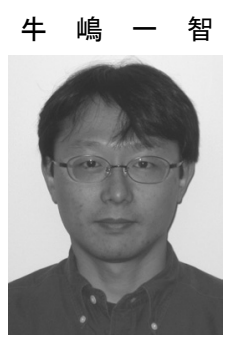

（非会員） 1971 年生。1993 年 3 月東京大学理 学部情報科学科卒業。1995 年同大学大学院理 学系研究科情報科学専攻修士課程終了。同年 （株）日立製作所入社。現在, 同社中央研究所 勤務。情報ライフサイクル管理, データーベー ス管理システム, バイオ情報処理の研究開発に 従事。情報処理学会, ACM SIGMOD 各会員。

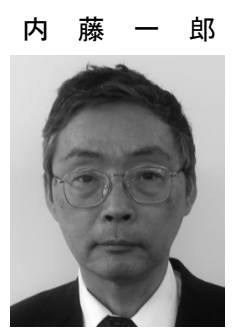

（非会員） 1948 年生。1971 年大阪大学基礎工 学部生物工学科卒業。同年（株）日立製作所入 社。現在, 同社システム開発研究所勤務。情報 ライフサイクル管理, トレーサビリティ等の研 究に従事。情報処理学会会員。

薦 田 憲 久

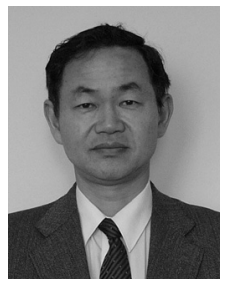

(正員) 1950 年生。 74 年大阪大学大学院工 学研究科電気工学専攻修士課程修了。同年(株) 日立製作所入社。システム開発研究所勤務。91 年大阪大学工学部情報システム工学科助教授, 92 年同大学教授。 2002 年 4 月より, 同大学大 学院情報科学研究科マルチメディア工学専攻教 授。工博。IEEEなどの会員。 